\title{
Furfuryl Alcohol. Part 1. A Near-infrared Study of the Self- and Heteroassociation of Furfuryl Alcohol in Carbon
} Tetrachloride

\author{
LIISA STRANDMAN
}

Department of Physical Chemistry, University of Helsinki, Meritullinkatu 1, SF-00170 Helsinki 17, Finland

Self-association of furfuryl alcohol in dilute carbon tetrachloride and cyclohexane solutions was studied by the near-infrared spectrometric method. The tendency of the alcohol to undergo self-association was found to be somewhat less than that of the ordinary simple alcohols. No signs of intramolecular hydrogen bonding could be detected. The heteroassociation of furfuryl alcohol with tetrahydrofuran, acetone, dimethyl sulfoxide, hexamethylphosphoramide, and pyridine was studied. Formation constants, frequency shifts, and thermodynamic parameters are given for these systems. The proton donor strength of furfuryl alcohol was found to be of about the same magnitude as that of the ordinary simple alcohols. The measurements were carried out at five different temperatures. The frequency shifts were found to depend only slightly upon the concentration of the base.

Relatively little is known about the association, complex formation, and molecular vibrations of the industrially important alcohol, furfuryl alcohol (FOH). The present paper is the first one in a series of papers that will deal with the properties of this alcohol. A study of the infrared, matrix infrared, and Raman spectra of furfuryl alcohol is in progress, and for this purpose some knowledge of the intramolecular hydrogen bonding as well as of the proton donor strength of this alcohol will be of value.

\section{EXPERIMENTAL}

Chemicals. Furfuryl alcohol (purissimum grade, Fluka AG.) was first dried with anhydrous $\mathrm{MgSO}_{4}$ and then distilled under reduced pressure through a $20 \mathrm{~cm}$ Vigreux column. The product, a colourless liquid with a refractive index of $n_{\mathrm{D}}{ }^{25}=1.483$, was stored under nitrogen gas atmosphere. Carbon tetrachloride (spectroscopic grade "Uvasol", E. Merck AG.) was dried with and stored over molecular sieve beads (4A from The British Drug Houses Ltd.). Cyclohexane (spectroscopic grade, E. Merck AG.) was treated with sodium wire and distilled through a $20 \mathrm{~cm}$ Vigreux column. The product was stored over molecular sieves. The remaining compounds, all commercially available, were carefully purified by distillation, except dimethyl sulfoxide which was purified by crystallization. The physical constants were checked against those reported in the literature.

Spectrophotometric measurements. The measurements were carried out with a Beckman DK-2A Ratio Recording Spectrophotometer. The scanning region was that of the fundamental $\mathrm{OH}$ vibration, from 3100 to $2700 \mathrm{~nm}$. Quartz cells of type 110-QI (Hellma, Müllheim/Baden) with path lengths of 1 to $50 \mathrm{~mm}$ were used in pairs of equal path length. In most cases the recordings were first made at $25^{\circ} \mathrm{C}$, then at the other temperatures, and finally a second time at $25^{\circ} \mathrm{C}$ to ascertain whether evaporation had occurred. The temperature varied within a few tenths of a degree during a single measurement. The spectrophotometer was purged with nitrogen at a rate of about $25 \mathrm{l} / \mathrm{h}$ to prevent moisture from condensing on the cell windows. Each series of measurements was started by scanning a zero absorbance baseline over the region in question. The concentrations were corrected for the variation in density of carbon tetrachloride with temperature. Only carbon tetrachloride (or cyclohexane) was in the reference cell when the self-association was studied, whereas in the heteroassociation studies the reference sample was a base-carbon tetrachloride solution of the same concentration as in the sample studied.

Calculations. The monomer-dimer equilibrium constants for self-association $K_{\mathrm{c}}\left(\mathrm{M}^{-1}\right)$ 
were calculated by the method of Liddel and Becker ${ }^{2}$ from initial slopes of plots of the apparent molar absorption coefficient $\varepsilon_{m}$ at the maximum of the monomer $v_{\mathrm{OH}}$ absorbance against the concentration.

When calculating equilibrium constants for 1:1 complexes it was assumed that no higher complexes existed. Furthermore, the measurements were carried out at alcohol concentrations so dilute that self-association could be neglected. The equilibrium equation can be written as $\mathrm{A}+\mathrm{B} \rightleftharpoons \mathrm{AB}$, where $\mathrm{A}$ indicates the proton donor (the alcohol), B the proton acceptor (the base), and $A B$ the complex formed. The following symbols are used: $c_{\mathrm{A}}{ }^{\circ}=$ original concentration of the alcohol, $c_{B}{ }^{\circ}=$ original concentration of the base, $c_{\mathrm{A}}$ and $c_{\mathrm{B}}=$ equilibrium concentrations of the alcohol and the base, respectively, $A^{\circ}$ and $A=$ absorbance of the free hydroxyl group before and after the complex formation, $\varepsilon=$ molar absorption coefficient of the alcohol, and $b=$ path length. The equilibrium constant can then be written as $K=c_{\mathrm{AB}} / c_{\mathrm{A}} c_{\mathrm{B}}$. In dilute solutions, activities can be replaced by the corresponding concentrations. Because $A^{\circ}=\varepsilon b c_{\mathrm{A}}^{\circ}, A=\varepsilon b c_{\mathrm{A}}$, and $c_{\mathrm{AB}}=$ $c_{\mathrm{A}}{ }^{\circ}-c_{\mathrm{A}}$, the equilibrium constants can be expressed as

$K=\frac{c_{\mathrm{A}}^{\circ}-c_{\mathrm{A}}}{c_{\mathrm{A}} c_{\mathrm{B}}}=\frac{A^{\circ}-A}{A\left[c_{\mathrm{B}}^{\circ}-\left(c_{\mathrm{A}}^{\circ}-c_{\mathrm{A}}\right)\right]}=$ $1-\mathrm{A} / \mathrm{A}^{\circ}$

$\left.\left.\overline{\left(A / A^{\circ}\right)\left[c_{\mathrm{B}}{ }^{\circ}-c_{\mathrm{A}}{ }^{\circ}(1-A\right.} \overline{A^{\circ}}\right)\right]$

The complexation enthalpy $\Delta H$ is evaluated by plotting In $K$ as a function of $1 / T$ :

$\ln K=-\Delta H / R T+$ constant. $\Delta H \sim \Delta H^{\circ}$ can be calculated from the slope of the straight line. The equations for calculating $\Delta G^{\circ}$ and $\Delta S^{\circ}$ are $\Delta G^{\circ}=-R T$ ln $K$ and $\Delta S^{\circ}=\left(\Delta H^{\circ}-\Delta G^{\circ}\right) / T$.

The estimated uncertainty in the shifts $\Delta v$ is $\pm 2 \mathrm{~cm}^{-1}$. The uncertainty limits of the association enthalpy $\Delta H$ are of the magnitude $4-15 \%$, the larger figure applying to the heteroassociation studies with tetrahydrofuran and acetone. The uncertainty of the equilibrium constant is about $5-10 \%$; also here the higher percentage relates to tetrahydrofuran and acetone.

\section{RESULTS AND DISCUSSION}

The self-association of furfuryl alcohol. Despite a number of investigations, no agreement about the self-association model of the alcohols has been reached. This is apparent in some of the more recent studies (Refs. 3-5). In most cases some average characteristic is measured and an attempt is made to accommodate the results obtained with the model considered. The advantage of the infrared method is that

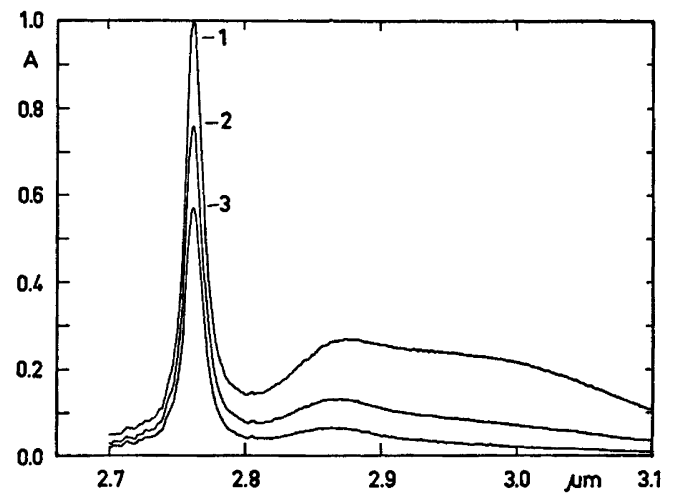

Fig. 1. Illustrative spectra of furfuryl alcohol (fundamental region of the $v_{\mathrm{OH}}$ vibration) in $\mathrm{CCl}_{4}$ at $25^{\circ} \mathrm{C}$. Concentrations (cell thickness 1 $\mathrm{mm}$ ) 1. $0.151 \mathrm{M}, 2.0 .103 \mathrm{M}, 3.0 .072 \mathrm{M}$.

concentrations of different species, i.e. monomers, dimers, and higher associates, can be estimated. The main problem is why the dimers give lower $\Delta v$ values than the higher associates. There are two contradictory views: either the hydrogen bonds in dimers are extraordinarily weak and in the higher polymers normal, or the hydrogen bonds in the dimers are normal and in the higher associates unusually strong. ${ }^{6}$

Fig. 1 presents spectra of furfuryl alcohol at different dilutions. No evidence of intramolecular hydrogen bonding can be seen in the plot. A possible explanation is that because the molecule as a whole is almost planar, the formation of a hydrogen bond between the $\pi$-electrons of the ring and the hydrogen in the $\mathrm{OH}$ group would lead to a strongly bent $\mathrm{C}-\mathrm{C}$ bond. More surprising, however, is the fact that no hydrogen bonding to the ring oxygen is apparent. As can be seen in Fig. 2a, such hydrogen bonding would result in an energetically possible ring of five atoms. According to $\mathrm{CNDO} / 2$ and INDO calculations the cis- and gauche-rotamers seem to prevail over the trans-conformer (Fig. 2b)..23<smiles></smiles>

(a)<smiles></smiles>

(b)
Fig. 2. Two conformers of furfuryl alcohol. (a), gauche; (b), trans.

Acta Chem. Scand. A 29 (1975) No. 6 


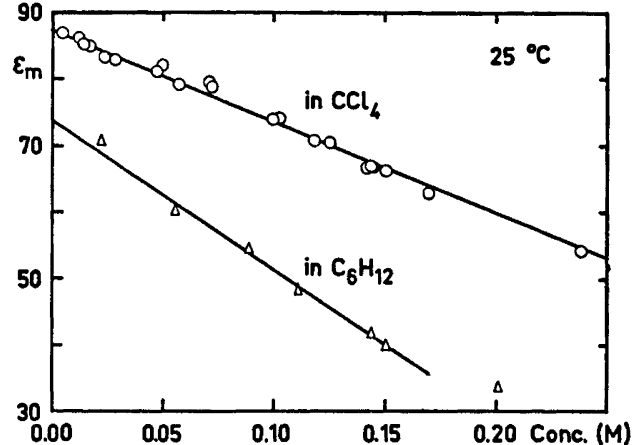

Fig. 3. A plot of the apparent molar absorption coefficient $\varepsilon_{\mathrm{m}}$ at the maximum of the monomer $v_{\mathrm{OH}}$ absorbance against the concentration of the alcohol (no base present).

These calculations imply that the interaction between the $\mathrm{OH}$ group and the ring oxygen is either very weak or does not exist. Thus the present author concludes that only intermolecular H-bonding can exist.

Calculations by Becker's method give the equilibrium dimerization constants $K_{2}\left(\mathrm{CCl}_{4}\right)=$ $0.78 \mathrm{M}^{-1}$ and $K_{2}\left(\mathrm{C}_{6} \mathrm{H}_{12}\right)=1.43 \mathrm{M}^{-1}$ for the self. association of furfuryl alcohol at $25^{\circ} \mathrm{C}$. The values of $\varepsilon_{m}$ are plotted against the concentration in Fig. 3. These plots are linear within the limits of experimental accuracy up to concentrations as high as $0.25 \mathrm{M}$. The non-zero limiting values of the slopes imply that the dimer is stable. ${ }^{2}$ Comparison with the literature

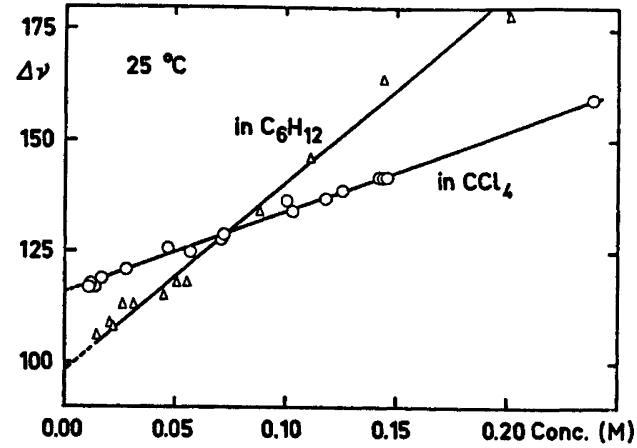

$F i g$. 4. A plot of the $\Delta v$ values of the alcohol dimer against the concentration of the alcohol.

values for ethanol in carbon tetrachloride solutions, viz., $K=0.89^{7}$ or $K=0.76{ }^{8}$ at $25{ }^{\circ} \mathrm{C}$, shows that furfuryl alcohol may be slightly less associated than this most widely used reference alcohol. The values $K=0.95^{\circ}$ and $K=0.64^{10}$ at $25^{\circ} \mathrm{C}$ have also been reported for the dimerization of ethanol, but the calculation method is not that of Becker and thus the results cannot be compared directly.

The absorption maximum between $2840 \mathrm{~nm}<$ $\lambda<2900 \mathrm{~nm}$ (Fig. 1) can be considered as the dimer absorption band. According to Murty, ${ }^{5}$ alcohols and phenols generally give values of about $125 \mathrm{~cm}^{-1}$ for the monomer-dimer shift $\Delta v$. It is obvious that the absorption maximum at lower frequencies is due to the higher associates.

Table 1. Data on hydrogen bonding between furfuryl alcohol (FOH) and various bases in $\mathrm{CCl}_{4}$ at $25^{\circ} \mathrm{C}$. Some literature values are included for comparison. THF $=$ tetrahydrofuran, $\mathrm{DMSO}=$ dimethyl sulfoxide, and HMPA = hexamethylphosphoramide. The alcohol monomer absorbs at $3620 \mathrm{~cm}^{-1}\left(\mathrm{CCl}_{4}, 25{ }^{\circ} \mathrm{C}\right)$.

\begin{tabular}{|c|c|c|c|c|c|}
\hline System & $\Delta v / \mathrm{cm}^{-1}$ & $K_{11} / \mathrm{M}^{-1}$ & $\frac{-\Delta H^{\circ}}{\mathrm{kJ} \mathrm{mol}^{-1}}$ & $\frac{-\Delta G^{\circ}}{\mathrm{kJ} \mathrm{mol}^{-1}}$ & $\frac{-\Delta S^{\circ}}{\mathrm{kJ} \mathrm{mol}^{-1} \mathrm{~K}^{-1}}$ \\
\hline $\begin{array}{l}\text { FOH-THF } \\
\text { Phenol-THF }\end{array}$ & $\begin{array}{l}192 \\
285\end{array}$ & $\begin{array}{l}1.98 \\
13.6\end{array}$ & $\begin{array}{l}12.6 \\
16.7\end{array}$ & 1.69 & 36.5 \\
\hline $\begin{array}{l}\text { FOH-acetone } \\
\text { EtOH-acetone } e^{14} \\
\text { Phenol-acetone }^{15}\end{array}$ & $\begin{array}{l}128 \\
113 \\
193\end{array}$ & $\begin{array}{l}1.58 \\
1.14\end{array}$ & $\begin{array}{l}13.5 \\
12.1 \\
13.8\end{array}$ & 1.14 & 41.5 \\
\hline $\begin{array}{l}\text { FOH-DMSO } \\
\text { Phenol-DMSO }\end{array}$ & $\begin{array}{l}244 \\
350\left(20^{\circ} \mathrm{C}\right)\end{array}$ & 15.2 & $\begin{array}{l}18.1 \\
33.4\end{array}$ & 6.83 & 37.7 \\
\hline $\begin{array}{l}\text { FOH-HMPA } \\
\text { EtOH-HMPA }^{17} \\
\text { Phenol-HMPA }^{17}\end{array}$ & $\begin{array}{l}310 \\
271\end{array}$ & $\begin{array}{l}58.3 \\
30.5\end{array}$ & $\begin{array}{l}20.2 \\
19.8 \\
29.9\end{array}$ & 10.04 & 34.0 \\
\hline $\begin{array}{l}\text { FOH-pyridine } \\
\text { EtOH-pyridine }{ }^{18} \\
\text { Phenol-pyridine }^{19}\end{array}$ & $\begin{array}{l}340 \\
276 \\
492\left(20^{\circ} \mathrm{C}\right)\end{array}$ & $\begin{array}{l}4.46 \\
2.41\end{array}$ & $\begin{array}{l}18.0 \\
15.3 \\
29.3\end{array}$ & 3.69 & 47.9 \\
\hline
\end{tabular}




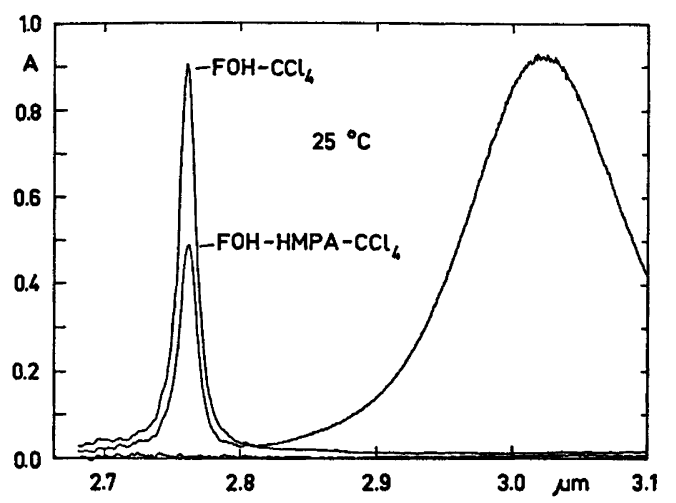

Fig. 5. A spectrum illustrating the contour of the absorption band in the heteroassociation studies. Alcohol concentration $0.0051 \mathrm{M}$ and the concentration of HMPA 0.0170 M (cell thickness $20 \mathrm{~mm}$ ).

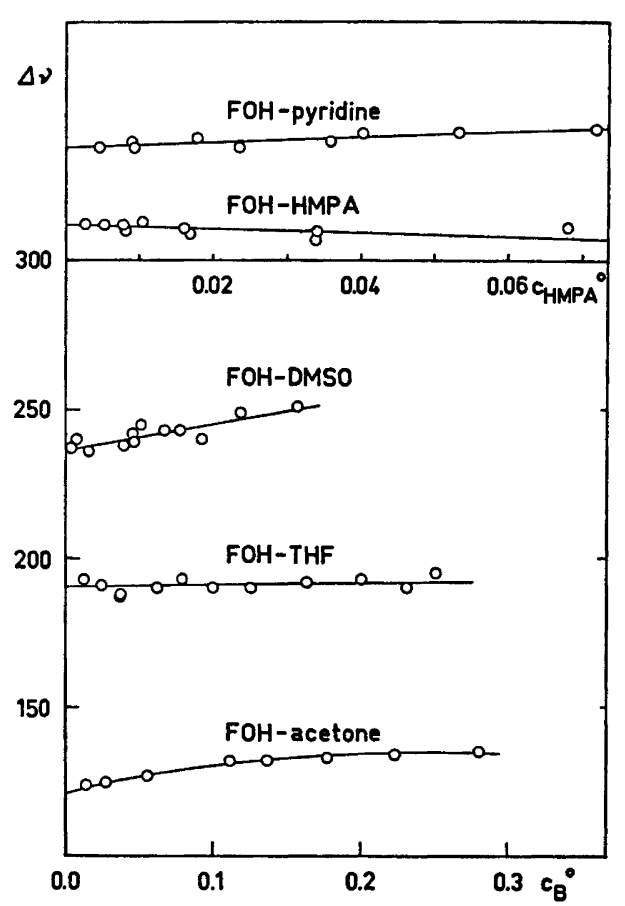

Fig. 6. Influence of the concentration of the base on $\Delta v$ of $\mathrm{FOH}$ - base complexes in $\mathrm{CCl}_{4}$ at $25^{\circ} \mathrm{C}$.

The $\Delta v$ value of the dimer was found to vary with the alcohol concentration. The results are given in Fig. 4. Kivinen et al. ${ }^{4}$ have presented a model for the association of alcohols in carbon tetrachloride solutions, which assumes the following sequence: monomer - cyclic dimer -
Table 2. Temperature dependence of the values of $\Delta v$ and $\partial v$ (complex)/ $\partial T$.

\begin{tabular}{|c|c|c|c|}
\hline System & $\frac{T}{{ }^{\circ} \mathrm{C}}$ & $\frac{\Delta v}{\mathrm{~cm}^{-1}}$ & $\frac{\partial v(\text { complex }) / \partial T}{\mathrm{~cm}^{-1} K^{-1}}$ \\
\hline FOH-THF & $\begin{array}{c}0.5 \\
15 \\
25 \\
35 \\
50\end{array}$ & $\begin{array}{l}197 \\
193 \\
192 \\
187 \\
183\end{array}$ & $0.28\left(0-50^{\circ} \mathrm{C}\right)$ \\
\hline FOH-acetone & $\begin{array}{c}0.5 \\
15 \\
25 \\
35 \\
50\end{array}$ & $\begin{array}{l}145 \\
137 \\
132 \\
128 \\
117\end{array}$ & $0.57\left(0-50^{\circ} \mathrm{C}\right)$ \\
\hline FOH-DMSO & $\begin{array}{l}0.7 \\
15 \\
25 \\
35 \\
50\end{array}$ & $\begin{array}{r}252 \\
248 \\
244 \\
239 \\
.231\end{array}$ & $0.43\left(0-50^{\circ} \mathrm{C}\right)$ \\
\hline FOH-HMPA & $\begin{array}{c}0.5 \\
15 \\
25 \\
35 \\
50\end{array}$ & $\begin{array}{l}317 \\
316 \\
308 \\
307 \\
305\end{array}$ & $0.24\left(0-50^{\circ} \mathrm{C}\right)$ \\
\hline FOH-pyridine & $\begin{array}{c}0.3 \\
15 \\
25 \\
35 \\
50\end{array}$ & $\begin{array}{l}351 \\
346 \\
340 \\
335 \\
331\end{array}$ & $0.40\left(0-50^{\circ} \mathrm{C}\right)$ \\
\hline
\end{tabular}

open dimer - open trimer and/or higher linear associates - cyclic trimer and/or tetramer. If only the infrared results are available, it is difficult to say anything definite in this particular case about the structures of the associates. Some preliminary research has been done on the dielectric properties of furfuryl alcohol. In carbon tetrachloride solutions the KirkwoodFröhlich correlation factor $g$ (Refs. 11 and 12) seems to exceed unity even in dilute solutions. That could imply a favourably parallel arrangement of the alcohol molecules and thus the linear structures even for dimers would be probable. $\Delta v(\mathrm{dim})$ in cyclohexane varies more with the concentration of the alcohol than $\Delta v$ (dim) in carbon tetrachloride. Moreover, the association is stronger in the former solvent than in the latter.

The heteroassociation of furfuryl alcohol. The heteroassociation of furfuryl alcohol was studied by varying the acceptor strength of the proton acceptors employed: one acceptor was reasonably weak (tetrahydrofuran), one was of me-

Acta Chem. Scand. A 29 (1975) No. 6 
dium strength (acetone) and three were strong (dimethyl sulfoxide, hexamethylphosphoramide, and pyridine). In all these cases the shape of the $v_{\mathrm{OH}}$ absorption band of the complex was symmetrical; the values of the alcohol monomer-complex shift $\Delta v$ were easily estimated (Fig. 5). The results are given in Table 1 together with some literature values for ethanol and phenol. The data in Table 1 imply that the tendency of furfuryl alcohol to form complexes is approximately similar to that of ordinary simple alcohols.

It has been suggested ${ }^{20}$ that in the heteroassociation the value of $\Delta v$ would vary with the concentration of the base. Therefore different base concentrations were used in measuring values of $\Delta v$; the results are given in Fig. 6. It can be seen that the concentration dependence of $\Delta v$ is rather small. Joris and Schleyer have studied only the complex formation of meth. anol. Possibly $\Delta v$ of alcohols other than meth. anol does not vary considerably with the base concentration.

It has been reported in the literature that $\Delta v$ varies with temperature. Table 2 gives the results of a study of furfuryl alcohol as a function of temperature. As is seen, the temperature coefficient $\partial v$ (complex)/ $\partial T$ varies considerably for the systems studied. It diminishes with increasing size of the base molecule, from +0.57 for acetone to $+\mathbf{0 . 2 4}$ for hexamethylphosphoramide. Zdzienski and Wood ${ }^{21}$ have given two alternative explanations of this phenomenon. Either at the lower temperatures the solvent contracts and compresses the complex, thus producing shorter and stronger hydrogen bonds, or the multiplicity of association is increased on cooling. Since the spectra show the existence of higher than 1:1 complexes to be unlikely even at $0^{\circ} \mathrm{C}$, at least the latter of Zdzienski's and Wood's explanations is not applicable. A preferable explanation is a solvent effect on the hydrogen bond.

The suitability of carbon tetrachloride as an inert solvent in hydrogen bond studies has been discussed during the past few years. Although $\mathrm{CCl}_{4}$ is not as inert as desired, no suitable substitute for it has been found for infrared studies. Arnett and his coworkers ${ }^{22}$ have recently discussed this problem, concluding that carbon tetrachloride is quite a good solvent after all.
Acknowledgements. The author wishes to thank Professor Antti Kivinen for his valuable suggestions and critical comments during the course of this work. Support received through a research grant from the Emil Aaltonen Foundation is gratefully acknowledged.

\section{REFERENCES}

1. Strandman, L. Unpublished results.

2. Liddel, U. and Becker, E. D. Spectrochim. Acta 10 (1957) 70.

3. Duboc, C. Spectrochim. Acta 30 A (1974) 431,441 .

4. Kivinen, A., Murto, J., Korppi-Tommola, J. and Kuopio, R. Acta Chem. Scand. 26 (1972) 904.

5. Murty, T. S. S. R. Can. J. Chem. 48 (1970) 184.

6. Bellamy, L. J. Advances in Infrared Group Frequencies, Methuen, London 1968, Chapter 8.

7. Kivinen, A. and Murto, J. Suom. Kemistilehti $B \quad 40$ (1967) 6.

8. Blanks, R. F. and Prausnitz, J. M. J. Chem. Phys. 38 (1963) 1500.

9. Ibbitson, D. A. and Moore, L. F. Chem. Commun. (1965) 339.

10. Coburn, Jr., W. C. and Grunwald, E. J. J. Amer. Chem. Soc. 80 (1958) 1318.

11. Kirkwood, J. G. J. Chem. Phys. 7 (1939) 911.

12. Fröhlich, H. Theory of Dielectrics, Clarendon Press, Oxford 1958, p. 36.

13. Singh, S. and Rao, C. N. R. J. Amer. Chem. Soc. 88 (1966) 2142.

14. Kivinen, A., Murto, J. and Kilpi, L. Suom. Kemistilehti $B 40$ (1967) 301.

15. Joesten, M. D. and Drago, R. S. J. Amer. Chem. Soc. 84 (1962) 3817.

16. Gramstad, T. Spectrochim. Acta 19 (1963) 829.

17. Kuopio, R. Personal communication.

18. Becker, E. D.Spectrochim. Acta 17 (1961) 436.

19. Gramstad, T. Acta Chem. Scand. 16 (1962) 807.

20. Joris, L. and von Raguè Schleyer, P. Tetrahedron 24 (1968) 5991.

21. Zdzienski, H. K. and Wood, J. L. J. Chem. Soc. Faraday Trans. 2 (1974) 409.

22. Arnett, E. M., Mitchell, E. J. and Murty, T. S. S. R. J. Amer. Chem. Soc. 96 (1974) 3875 .

23. Hasanein, A. A. and Kováč, S. Collect. Czech. Chem. Commun. 39 (1974) 3613.

Received February 7, 1975. 